\title{
Commentary: SWS Brain-Wave Music May Improve the Quality of Sleep: An EEG Study
}

\author{
Jennifer M. Johnson ${ }^{1,2 \star}$ and Simon J. Durrant ${ }^{2,3}$ \\ ${ }^{1}$ School of Health and Social Care, University of Lincoln, Lincoln, United Kingdom, ${ }^{2}$ Lincoln Sleep Research Centre, \\ University of Lincoln, Lincoln, United Kingdom, ${ }^{3}$ School of Psychology, University of Lincoln, Lincoln, United Kingdom
}

Keywords: slow-wave sleep, delta power, music, auditory cognitive neuroscience, sleep

\section{A Commentary on}

SWS Brain-Wave Music May Improve the Quality of Sleep: An EEG Study

by Gao, D., Long, S., Yang, H., Cheng, Y., Guo, S., Yu, Y., et al. (2020). Front. Neurosci. 14:67. doi: 10.3389/fnins.2020.00067

\section{OPEN ACCESS}

Edited by:

Josef P. Rauschecker,

Georgetown University, United States

Reviewed by:

Laura Verga,

Max Planck Institute for

Psycholinguistics, Netherlands

${ }^{*}$ Correspondence:

Jennifer M. Johnson

jjohnson@lincoln.ac.uk

Specialty section:

This article was submitted to Auditory Cognitive Neuroscience,

a section of the journal

Frontiers in Neuroscience

Received: 22 September 2020

Accepted: 11 January 2021

Published: 01 February 2021

Citation:

Johnson JM and Durrant SJ (2021) Commentary: SWS Brain-Wave Music May Improve the Quality of Sleep: An

EEG Study.

Front. Neurosci. 15:609169. doi: 10.3389/fnins.2021.609169
Sleep is important for maintaining health and general well-being. Improving sleep is becoming more important due to the growing prevalence of sleep disorders, with non-pharmacological sleep interventions increasing in popularity (de Niet et al., 2009; Ngo et al., 2013b). When comparing interventions, music-based were the most successful for improving subjective sleep quality (de Niet et al., 2009), using a range of music types including classical, jazz, and sedative (Chan et al., 2010; Chen et al., 2014; Shum et al., 2014), as well as sounds including white (Afshar et al., 2016) and pink noise (Zhou et al., 2012). The effect of music on specific sleep stages, however, is less well-known with relatively few studies to date using objective sleep quality measures (Cordi et al., 2019).

Sleep consists of rapid eye-movement (REM) and non-rapid eye-movement (NREM) components, with NREM comprising various stages including slow-wave sleep (SWS) (Rechtschaffen and Kales, 1968), which is dominated by slow-wave activity (SWA) (0.5-4 Hz) consisting of delta and slow waves $(<2 \mathrm{~Hz}$ ) (Dijk et al., 1993). To date, music interventions have increased the amount of SWS (Chen et al., 2014; Cordi et al., 2019) and REM sleep (Chang et al., 2012), without changing delta power during SWS (Lazic and Ogilvie, 2007). To our knowledge, Gao et al. (2020) are the first to explore the impact of brain-wave music created from EEG during REM sleep.

Gao et al. (2020) explored the impact of SWS music $(n=11)$, REM sleep music $(n=13)$, and white noise $(n=9)$ played for 20 min before bedtime for 6 days on objective measures of sleep quality, including spectral power. The brain-wave music was created using the amplitude, period and average power of each sleep stage and translated into music pitch, duration, volume, and timbre using power law. Using this method, they aimed to compare the effects of each type of music on sleep quality and neural activation. The key finding was that after SWS brain-wave music, delta power significantly reduced, which the authors interpreted as a positive effect on sleep quality.

This is an important area of research, but in this case we offer an alternative interpretation of the results. The authors argue that lower delta power is indicative of improved sleep and SWS, citing previous research (Svetnik et al., 2017) and interpret the reduction in delta power as a reduced homeostatic pressure for delta power, as found in older adults (Landolt et al., 1996; Landolt and Borbély, 2001). However, Svetnik et al. (2017) actually found a reduction in delta power in younger adults (the age group in this study) was associated with insomnia, i.e., poorer sleep quality. Furthermore, while reduced delta activity could indicate a reduction in homeostatic sleep pressure, this is unlikely to be the case given that sleep latency after SWS music was significantly lower, and sleep efficiency somewhat higher, which are both associated with increased homeostatic sleep 
pressure (Dijk et al., 2010; Dijk and Landolt, 2019), while the duration of SWS was unchanged. These results suggest that the reduction of delta power is instead indicative of an impairment. This view results from both the positive consequences of increasing delta power and the negative consequences of prolonged delta power reduction (both clinically and cognitively), which is why research has focused on increasing delta power for optimal sleep quality (Marshall et al., 2006; Santiago et al., 2019).

SWS is the sleep stage most commonly associated with sleep quality due to its restorative nature (Åkerstedt et al., 1997; Dijk, 2009). To infer cause and effect, studies have focused on (a) enhancing SWS using stimulation, resulting in improvements to learning and health outcomes (Besedovsky et al., 2017; Johnson and Durrant, 2018); and (b) suppressing SWS, increasing the risk of type 2 diabetes through impaired insulin and glucose (Tasali et al., 2008; Herzog et al., 2013) and negatively affecting cognitive performance (Ferrara et al., 2000). These results collectively suggest that there are benefits to increasing delta power, whilst reducing delta power is problematic for a range of outcomes.

The brain-wave music intervention therefore appears to be unsuccessful and we suggest there are three possible reasons for this. Successful interventions use entrainment (Marshall et al., 2006; Ngo et al., 2013a) which may not be present in the current study. Auditory closed-loop stimulation entrains the sounds to the up-states of the slow-oscillations, with the slope of each individual participants slow-oscillation being measured, which then increases the amplitudes and power (Ngo et al., 2013a). The SWS brain-wave music was not, however, entrained to the SWA of each individual. Related to that, the music stimuli appeared to have no clear metrical structure and the tempo was nominally set to $120 \mathrm{bpm}$ for both conditions with no consistent beat present in reality, in spite of previous findings connecting

\section{REFERENCES}

Åkerstedt, T., Hume, K., Minors, D., and Waterhouse, J. (1997). Good sleep - its timing and physiological sleep characteristics. J. Sleep Res. 6, 221-229. doi: 10.1111/j.1365-2869.1997.00221.x

Afshar, F., Bahramnezhad, F., Asgari, P., and Shiri, M. (2016). Effect of white noise on sleep in patients admitted to a coronary care. J. Caring Sci. 5, 103-109. doi: $10.15171 /$ jcs.2016.011

Besedovsky, L., Ngo, H.-V. V., Dimitrov, S., Gassenmaier, C., Lehmann, R., and Born, J. (2017). Auditory closed-loop stimulation of EEG slow oscillations strengthens sleep and signs of its immune-supportive function. Nat. Commun. 8:1984. doi: 10.1038/s41467-017-02170-3

Chan, M. F., Chan, E. A., and Mok, E. (2010). Effects of music on depression and sleep quality in elderly people: a randomised controlled trial. Complement. Ther. Med. 18, 150-159. doi: 10.1016/j.ctim.2010.02.004

Chang, E. T., Lai, H. L., Chen, P. W., Hsieh, Y. M., and Lee, L. H. (2012). The effects of music on the sleep quality of adults with chronic insomnia using evidence from polysomnographic and self-reported analysis: a randomized control trial. Int. J. Nurs. Stud. 49, 921-930. doi: 10.1016/j.ijnurstu.2012.02.019

Chen, C. K., Pei, Y. C., Chen, N. H., Huang, L. T., Chou, S. W., Wu, K. P., et al. (2014). Sedative music facilitates deep sleep in young adults. J. Altern. Complement. Med. 20, 312-317. doi: 10.1089/acm.2012.0050

Cordi, M. J., Ackermann, S., and Rasch, B. (2019). Effects of relaxing music on healthy sleep. Sci. Rep. 9:9079. doi: 10.1038/s41598-019-45608-y
EEG periodicity to tempo (Fujioka et al., 2012). More generally, the particular mapping of EEG to music parameters is highly questionable, with no inherent relationship between average spectral power and musical timbre, for example. Finally, the stimulation was performed for only $20 \mathrm{~min}$ prior to sleep, when successful interventions performed prior to sleep/during sleep onset have been performed for a longer duration, e.g., $90 \mathrm{~min}$ (Ngo et al., 2013b). Similarly, performing auditory stimulation during SWS is more successful for improving SWA than prior to sleep/sleep onset (Ngo et al., 2013a,b). We therefore suggest that lack of entrainment, arbitrary EEG-music mapping and unfortunate stimulus timing may have contributed to the lack of success of the intervention.

In conclusion, we believe that this research does not show a positive effect of SWS brain-wave music on sleep quality; quite the contrary. We agree, however, that it is an important question and using music with characteristics specific to individual sleep stages is a positive development. The implementation in this case, however, seems to be flawed and as such has led to inconclusive findings. Future research should, therefore, focus on improving the implementation, incorporating entrainment, appropriate stimulus timing, and a music-EEG mapping grounded in existing evidence from cognitive neuroscience.

\section{AUTHOR CONTRIBUTIONS}

JJ and SD wrote the paper. Both authors contributed to the article and approved the submitted version.

\section{ACKNOWLEDGMENTS}

We would like to thank the authors of the original paper.

de Niet, G. J., Tiemens, B. G., Kloos, M. W., and Hutschemaekers, G. J. M. (2009). Review of systematic reviews about the efficacy of non-pharmacological interventions to improve sleep quality in insomnia. Int. J. Evid. Based. Healthc. 7, 233-242. doi: 10.1111/j.1744-1609.2009.00142.x

Dijk, D.-J. (2009). Regulation and functional correlates of slow wave sleep. J. Clin. Sleep Med. 5, 13535-13539. doi: 10.5664/jcsm.5.2S.S6

Dijk, D.-J., Hayes, B., and Czeisler, C. A. (1993). Dynamics of electroencephalographic sleep spindles and slow wave activity in men: effect of sleep deprivation. Brain Res. 626, 190-199. doi: 10.1016/0006-8993(93)9 0579-C

Dijk, D.-J., and Landolt, H.-P. (2019). "Sleep physiology, circadian rhythms, waking performance and the development of sleep-wake therapeutics," in SleepWake Neurobiology and Pharmacology, eds H.-P. Landolt and D.-J. Dijk (Cham: Springer International Publishing), 441-481. doi: 10.1007/164_2019_243

Dijk, D. J., Groeger, J. A., Stanley, N., and Deacon, S. (2010). Age-related reduction in daytime sleep propensity and nocturnal slow wave sleep. Sleep 33, 211-223. doi: 10.1093/sleep/33.2.211

Ferrara, M., Gennaro, L., Casagrande, M., and Bertini, M. (2000). Selective slow-wave sleep deprivation and time-of-night effects on cognitive performance upon awakening. Psychophysiology 37, 440-446. doi: 10.1111/1469-8986.3740440

Fujioka, T., Trainor, L. J., Large, E. W., and Ross, B. (2012). Internalized timing of isochronous sounds is represented in neuromagnetic beta oscillations. J. Neurosci. 32, 1791-1802. doi: 10.1523/JNEUROSCI.4107-11.2012 
Gao, D., Long, S., Yang, H., Cheng, Y., Guo, S., Yu, Y., et al. (2020). SWS brainwave music may improve the quality of sleep: an EEG study. Front. Neurosci. 14:67. doi: 10.3389/fnins.2020.00067

Herzog, N., Jauch-Chara, K., Hyzy, F., Richter, A., Friedrich, A., Benedict, C., et al. (2013). Selective slow wave sleep but not rapid eye movement sleep suppression impairs morning glucose tolerance in healthy men. Psychoneuroendocrinology 38, 2075-2082. doi: 10.1016/j.psyneuen.2013.03.018

Johnson, J. M., and Durrant, S. J. (2018). The effect of cathodal transcranial direct current stimulation during rapid eye-movement sleep on neutral and emotional memory. R. Soc. Open Sci. 5:172353. doi: 10.1098/rsos.172353

Landolt, H. P., and Borbély, A. A. (2001). Age-dependent changes in sleep EEG topography. Clin. Neurophysiol. 112, 369-377. doi: 10.1016/S1388-2457(00)00542-3

Landolt, H. P., Dijk, D. J., Achermann, P., and Borbély, A. A. (1996). Effect of age on the sleep EEG: slow-wave activity and spindle frequency activity in young and middle-aged men. Brain Res. 738, 205-212. doi: 10.1016/S0006-8993(96)00770-6

Lazic, S. E., and Ogilvie, R. D. (2007). Lack of efficacy of music to improve sleep: a polysomnographic and quantitative EEG analysis. Int. J. Psychophysiol. 63, 232-239. doi: 10.1016/j.ijpsycho.2006.10.004

Marshall, L., Helgadóttir, H., Mölle, M., and Born, J. (2006). Boosting slow oscillations during sleep potentiates memory. Nature 444, 610-613. doi: $10.1038 /$ nature 05278

Ngo, H.-V., Martinetz, T., Born, J., and Mölle, M. (2013b). Auditory closedloop stimulation of the sleep slow oscillation enhances memory. Neuron 78, 545-553. doi: 10.1016/j.neuron.2013.03.006

Ngo, H.-V. V., Claussen, J. C., Born, J., and Mölle, M. (2013a). Induction of slow oscillations by rhythmic acoustic stimulation. J. Sleep Res. 22, 22-31. doi: 10.1111/j.1365-2869.2012.01039.x

Rechtschaffen, A., and Kales, A. (1968). A Manual of Standardised Terminology, Techniques and Scoring System for Sleep Stages of Human Subjects. 1st Edn. Los
Angeles, CA: Brain Information Service/Brain Research Institute: Elsevier Inc. doi: 10.1016/B978-1-4557-1267-0.00003-5

Santiago, J. C. P., Ngo, H. V., Jickeli, C., Peter, A., and Hallschmid, M. (2019). Intensifying sleep slow oscillations does not improve metabolic control in healthy men. Psychoneuroendocrinology 99, 1-7. doi: 10.1016/j.psyneuen.2018.08.028

Shum, A., Taylor, B. J., Thayala, J., and Chan, M. F. (2014). The effects of sedative music on sleep quality of older community-dwelling adults in singapore. Complement. Ther. Med. 22, 49-56. doi: 10.1016/j.ctim.2013. 11.003

Svetnik, V., Snyder, E. S., Ma, J., Tao, P., Lines, C., and Herring, W. J. (2017). EEG spectral analysis of NREM sleep in a large sample of patients with insomnia and good sleepers: effects of age, sex and part of the night. J. Sleep Res. 26, 92-104. doi: 10.1111 /jsr. 12448

Tasali, E., Leproult, R., Ehrmann, D. A., and Van Cauter, E. (2008). Slow-wave sleep and the risk of type 2 diabetes in humans. Proc. Natl. Acad. Sci. U.S.A. 105, 1044-1049. doi: 10.1073/pnas.0706446105

Zhou, J., Liu, D., Li, X., Ma, J., Zhang, J., and Fang, J. (2012). Pink noise: effect on complexity synchronization of brain activity and sleep consolidation. J. Theor. Biol. 306, 68-72. doi: 10.1016/j.jtbi.2012.04.006

Conflict of Interest: The authors declare that the research was conducted in the absence of any commercial or financial relationships that could be construed as a potential conflict of interest.

Copyright (c) 2021 Johnson and Durrant. This is an open-access article distributed under the terms of the Creative Commons Attribution License (CC BY). The use, distribution or reproduction in other forums is permitted, provided the original author(s) and the copyright owner(s) are credited and that the original publication in this journal is cited, in accordance with accepted academic practice. No use, distribution or reproduction is permitted which does not comply with these terms. 